\title{
Composite Right / Left Handed (CRLH) based devices for microwave applications
}

\author{
Stefan Simion $¥$, Romolo Marcelli, Giancarlo Bartolucci”, Florea Craciunoiu ${ }^{\ddagger}$, \\ Andrea Lucibello*, Giorgio De Angelis*, Andrei A. Muller‡, Alina Cristina Bunea ${ }^{\ddagger}$, \\ Gheorghe Ioan Sajin $\neq$ \\ ¥National Institute for Research and Development in Microtechnologies, Bucharest, \\ Romania \\ ${ }^{*}$ CNR - Institute for Microelectronics and Microsystems, Rome \\ Italy \\ \# University of Rome “Tor Vergata”, Department of Electronics Engineering, Rome
} Italy

\section{Introduction}

Metamaterials (MMs) became a very actual topic in the present research interest field, due to their unusual but interesting characteristics, not encountered in nature (Veselago, 1968) (Engheta \& Ziolkowski, 2005). A way to obtain media having MM characteristics is to develop circuits which, under certain conditions, model the MMs properties. Using different lattice structures or periodic repetition of unit cells, different types of two-dimensional MMs have been suggested (Sievenpiper et.al., 1999; Caloz \& Itoh, 2003).

A particular class of MMs consists of artificial LH (Left-Hand) transmission lines, which may be obtained using series capacitors and parallel connected inductors. With this approach and using SMDs (surface mounted devices), circuits such as branch couplers (Lin et al., 2003) and ring couplers (Okabe et al., 2004) operating up to a few $\mathrm{GHz}$, have been reported. The main advantage of these circuits compared to the classical ones is the dual frequency response for any two frequency ratio.

For higher microwave frequencies, it is more convenient to replace SMD capacitors and inductors with interdigital capacitors and short-ended transmission lines, respectively, in microstrip or CPW configuration. Taking into account the series equivalent inductance of the capacitors and the parallel equivalent capacitance of the short-ended transmission lines (working as inductors, at their own resonance frequency), CRLH (omposite Right / Left Handed) cells are obtained (Lai et al., 2004). The CRLH cells open a new class of devices and applications such as backward-wave directional couplers (Caloz et al., 2004), tunable radiation angle and beamwidth antennas (Lim et al., 2004), zeroth-order resonator antennas (Sanada et al., 2004). Other new expected research directions may be found in literature (see for example Caloz \& Itoh, 2005).

In the last few years, CPW (CoPlanar Waveguide) CRLH based devices were investigated and fabricated on semiconductor substrate, such as bandpass filters (C. Li et al., 2007 and W. 
Tong et al, 2007), resonating antennas (Simion et al., 2007-a,b) and directional couplers (Simion et al., 2008-a,b). The main advantage of using semiconductor substrate for these devices is the possibility to integrate them monolithically in more complex circuits.

Very interesting applications can also be developed using CRLH based devices supported by magnetically biased ferrite. Recently, authors compared four related CRLH leaky-wave antennas where the CRLH structure dispersion was controlled by an applied magnetic field, for fixed frequency external tuning (Kodera \& Caloz, 2008). Also, a CPW CRLH resonating antenna having a magnetically polarized ferrite as supporting substrate has been recently investigated and reported (Sajin et al., 2009).

The results presented in this chapter are focused on the results obtained by the authors in the field of CPW CRLH based devices, such as a directional coupler and a resonating antenna, both fabricated on silicon substrate, but also a resonating antenna manufactured on magnetically biased ferrite.

\section{RH, LH and CRLH Transmission Lines}

The transmission lines used in practice (microstrip, CPW etc.) are homogenous transmission media. They may be modeled with equivalent circuits consisting of distributed elements, which are obtained by cascading a large enough number of cells (so that the length of a cell becomes much shorter in comparison to the wavelength), each cell being a series inductance and a parallel capacitance, which will be further addressed as RH (Right-Handed)-TL Transmission Line). For the transmission line based on RH-TL cells, the phase velocity and the group velocity have positive values.

A transmission line, with a negative phase velocity (but with a positive group velocity, like for the RH-TL) would be useful in some applications. As equivalent circuit, this transmission line must consist of a large enough number of cells, each one being a series distributed capacitance and a parallel distributed inductance, further referred to as LH (LeftHanded) - TL. This type of transmission line does not exist in practice, but an artificial transmission line consisting of lumped elements can model the LH-TL behavior.

The artificial LH-TL is fabricated by using capacitors and inductors. Taking the series inductance of the capacitors and the parallel capacitance of the inductors into account, a more complicated equivalent circuit for an LH-TL cell is obtained. The structure (cell) having an equivalent circuit containing both the RH-TL equivalent circuit as well as the LHTL equivalent circuit is known as CRLH (Composite Right / Left Handed). By cascading CRLH cells, CRLH-TLs are obtained. Depending on the frequency, the CRLH-TL may have RH-TL or LH-TL behavior.

The propagation constant and the characteristic impedance for the RH-TL, LH-TL and CRLH-TL are reviewed in the next sections (see also Caloz \& Itoh, 2006).

\section{1. $\mathrm{RH}-\mathrm{TL}$ and $\mathrm{LH}-\mathrm{TL}$}

The equivalent circuits of a cell, for RH-TL and LH-TL are shown in Fig.1 (a) and (b). 


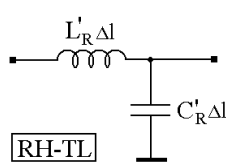

(a)

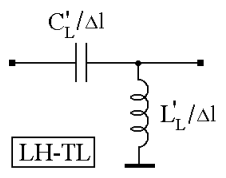

(b)

Fig. 1. Equivalent circuits with distributed elements, for a cell of RH-TL (a) and LH-TL (b).

In these circuits, $L_{R}^{\prime}, C_{R}^{\prime}$ and $L_{L}^{\prime}, C_{L}^{\prime}$ are the distributed inductance and capacitance for RH-TL and LH-TL respectively. For these equivalent circuits, the propagation constant and the characteristic impedance can be determined with the following formulas:

$$
Y=\sqrt{Z^{\prime}(\omega) Y^{\prime}(\omega)}=\alpha+j \beta \quad \text { and } \quad Z_{c}=\sqrt{\frac{Z^{\prime}(\omega)}{Y^{\prime}(\omega)}}
$$

respectively, where $Z^{\prime}(\omega)$ and $Y^{\prime}(\omega)$ are the impedance of the series branch and the admittance of the parallel branch (see Fig.1 a,b), $\alpha$ is the attenuation constant and $\beta$ is the phase constant.

If the line is lossless $(\alpha=0)$, then the propagation constant is pure imaginary, while the impedance is pure real. For RH-TL we can write (see Fig.1 a):

$$
Z^{\prime}(\omega)=j \omega L_{R}^{\prime} \quad \text { and } \quad Y^{\prime}(\omega)=j \omega C_{R}^{\prime}
$$

By inserting $(2 a, b)$ in $(1 a, b)$, we get:

$$
\beta_{\mathrm{RH}-\mathrm{TL}}=\omega \sqrt{\mathrm{L}_{\mathrm{R}}^{\prime} \mathrm{C}_{\mathrm{R}}^{\prime}}>0 \text { and } \quad \mathrm{Z}_{\mathrm{C}, \mathrm{RH}-\mathrm{TL}}=\sqrt{\frac{\mathrm{L}_{\mathrm{R}}^{\prime}}{\mathrm{C}_{\mathrm{R}}^{\prime}}}
$$

For LH-TL, it may be written (see Fig.1 b):

$$
Z^{\prime}(\omega)=\frac{1}{j \omega C_{L}^{\prime}} \quad \text { and } \quad Y^{\prime}(\omega)=\frac{1}{j \omega L_{L}^{\prime}}
$$

By inserting $(4 a, b)$ in $(1 a, b)$, we get:

$$
\beta_{\mathrm{LH}-\mathrm{TL}}=-\frac{1}{\omega \sqrt{\mathrm{L}_{\mathrm{L}}^{\prime} \mathrm{C}_{\mathrm{L}}^{\prime}}}<0 \text { and } \mathrm{Z}_{\mathrm{C}, \mathrm{LH}-\mathrm{TL}}=\sqrt{\frac{\mathrm{L}_{\mathrm{L}}^{\prime}}{\mathrm{C}_{\mathrm{L}}^{\prime}}}
$$


The equations ( 3 a) and (5 a) are the dispersion equations for RH-TL and LH-TL, respectively. The qualitative graphic representation of these equations is given in Fig.2.

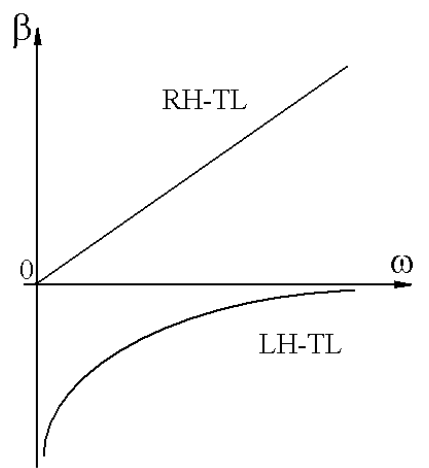

Fig. 2. Graphic representation of the dispersion equations for lossless RH-TL and LH-TL

The phase velocity, $v_{f}=\frac{\omega}{\beta}$ obtained from the dispersion equations $(3 a)$ and $(5 a)$ is positive for RH-TL and negative for LH-TL. The group velocity, $v_{g}=\frac{1}{d \beta}$, is positive for d $\omega$

both RH-TL and LH-TL. Therefore, the energy transport is, from generator to load in both cases, but for LH-TL, due to the fact that the phase velocity is negative, the wave is propagated backwards (from load to generator).

\subsection{CRLH transmission lines}

As mentioned above, the equivalent circuit of CRLH-TL is a combination of the equivalent circuits for RH-TL and LH-TL. The equivalent circuit for CRLH-TL is given in Fig.3, where, similar to RH-TL and LH-TL, $\Delta \mathrm{l}$ must be small enough compared to the wavelength.

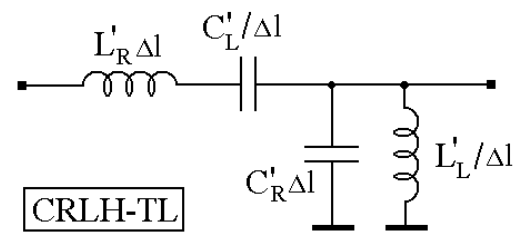

Fig. 3. The distributed equivalent circuit for a cell of CRLH-TL.

For the circuit given in Fig.3: 


$$
Z^{\prime}(\omega)=j\left(\omega L_{R}^{\prime}-\frac{1}{\omega C_{L}^{\prime}}\right) \text { and } Y^{\prime}(\omega)=j\left(\omega C_{R}^{\prime}-\frac{1}{\omega L_{L}^{\prime}}\right)
$$

Using (6a,b), with the relations ( 1 a) and $\alpha=0$ (lossless circuit), we get:

$$
\beta_{\mathrm{CRLH}-\mathrm{TL}}=-\sqrt{\left(\omega \mathrm{L}_{\mathrm{R}}^{\prime}-\frac{1}{\omega \mathrm{C}_{\mathrm{L}}^{\prime}}\right)\left(\omega \mathrm{C}_{\mathrm{R}}^{\prime}-\frac{1}{\omega \mathrm{L}_{\mathrm{L}}^{\prime}}\right)}<0 \text { for } \omega<\omega \Gamma_{1}
$$

and

$$
\beta_{\mathrm{CRLH}-\mathrm{TL}}=+\sqrt{\left(\omega \mathrm{L}_{\mathrm{R}}^{\prime}-\frac{1}{\omega \mathrm{C}_{\mathrm{L}}^{\prime}}\right)\left(\omega \mathrm{C}_{\mathrm{R}}^{\prime}-\frac{1}{\omega \mathrm{L}_{\mathrm{L}}^{\prime}}\right)}>0 \text { for } \omega>\omega \Gamma_{2}
$$

where:

$$
{ }^{\omega} \Gamma_{1}=\min \left[\frac{1}{\sqrt{L_{R}^{\prime} C_{L}^{\prime}}} ; \frac{1}{\sqrt{L_{L}^{\prime} C_{R}^{\prime}}}\right] \text { and } \quad \omega_{\Gamma_{2}}=\max \left[\frac{1}{\sqrt{L_{R}^{\prime} C_{L}^{\prime}}} ; \frac{1}{\sqrt{L_{L}^{\prime} C_{R}^{\prime}}}\right]
$$

For $\omega \in\left(\omega_{\Gamma_{1}}, \omega_{\Gamma_{2}}\right)$, the phase constant, $\beta$, is an imaginary number, therefore the propagation constant, $\gamma$, is a real number, which means that the signal on the line is attenuated. Therefore, for $\omega \in\left(\omega \Gamma_{1}, \omega \Gamma_{2}\right)$, the circuit behaves as a band-stop filter. If ${ }^{\omega} \Gamma_{1}={ }^{\omega} \Gamma_{2}$, then there is no stop-band.

The circuit for which $\omega_{\Gamma_{1}} \neq \omega_{\Gamma_{2}}$ is called an unbalanced circuit, while the circuit for which ${ }^{\omega} \Gamma_{1}={ }^{\omega} \Gamma_{2}$ is called a balanced circuit.

By simply looking at the equations $(8 \mathrm{a}, \mathrm{b})$, we get $\omega_{\Gamma_{1}}=\omega^{\omega} \Gamma_{2}$ if:

$$
\mathrm{L}_{\mathrm{R}}^{\prime} \mathrm{C}_{\mathrm{L}}^{\prime}=\mathrm{L}_{\mathrm{L}}^{\prime} \mathrm{C}_{\mathrm{R}}^{\prime}
$$

In this case, we replace the frequencies ${ }^{\omega} \Gamma_{1}$ and $\omega^{\omega} \Gamma_{2}$ with $\omega_{0}$ getting the following expression: 


$$
\omega_{0}=\frac{1}{\sqrt{\mathrm{L}_{\mathrm{R}}^{\prime} \mathrm{C}_{\mathrm{L}}^{\prime}}}=\frac{1}{\sqrt{\mathrm{L}_{\mathrm{L}}^{\prime} \mathrm{C}_{\mathrm{R}}^{\prime}}}=\frac{1}{\sqrt[4]{\mathrm{L}_{\mathrm{R}}^{\prime} \mathrm{C}_{\mathrm{L}}^{\prime} \mathrm{L}_{\mathrm{L}}^{\prime} \mathrm{C}_{\mathrm{R}}^{\prime}}}
$$

Also, for the balanced circuit, from the equations $(7 \mathrm{a}, \mathrm{b})$ and (10), $\beta=0$.

Analyzing the dispersion equations $(7 \mathrm{a}, \mathrm{b})$, it results that, for $\omega<\omega_{\Gamma_{1}}$ (or $\omega<\omega_{0}$, for the balanced circuit), the line has a LH-TL behavior, while for $\omega>\omega_{\Gamma_{2}}$ (or $\omega>\omega_{0}$, for the balanced circuit), the line has a RH-TL behavior.

The equations $(7 \mathrm{a}, \mathrm{b})$ are the dispersion equations for CRLH-TL. The graphic representation (qualitative) of these dispersion equations, for the unbalanced and balanced circuits, are shown in Fig.4 (a) and Fig.4 (b), respectively.

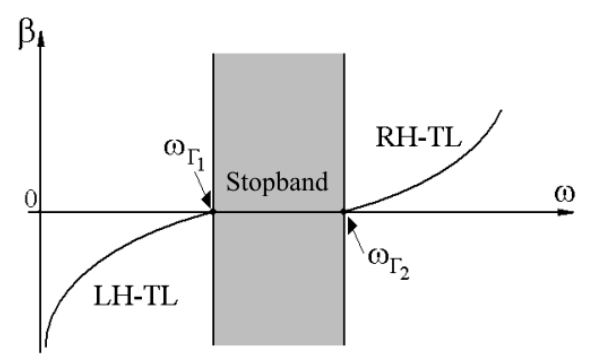

(a)

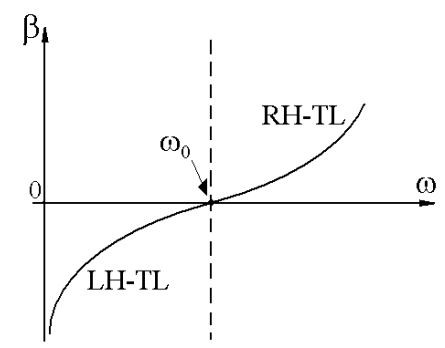

(b)

Fig. 4. Graphic representation of the dispersion equations for CRLH-TL, for unbalanced (a) and balanced (b) cases.

The characteristic impedance for CRLH-TL in an unbalanced circuit is obtained by inserting $(6 a, b)$ in $(1 b)$. The following formula is obtained:

$$
\mathrm{Z}_{\mathrm{C}, \mathrm{CRLH}-\mathrm{TL}}=\sqrt{\frac{\mathrm{L}_{\mathrm{L}}^{\prime}}{\mathrm{C}_{\mathrm{L}}^{\prime}}} \cdot \sqrt{\frac{\omega^{2} \mathrm{~L}_{\mathrm{R}}^{\prime} \mathrm{C}_{\mathrm{L}}^{\prime}-1}{\omega^{2} \mathrm{~L}_{\mathrm{L}}^{\prime} \mathrm{C}_{\mathrm{R}}^{\prime}-1}}
$$

If the circuit is balanced, then, with the equation (9), from (11) we get:

$$
\mathrm{Z}_{\mathrm{C}, \mathrm{CRLH}-\mathrm{TL}}=\sqrt{\frac{\mathrm{L}_{\mathrm{L}}^{\prime}}{\mathrm{C}_{\mathrm{L}}^{\prime}}}=\sqrt{\frac{\mathrm{L}_{\mathrm{R}}^{\prime}}{\mathrm{C}_{\mathrm{R}}^{\prime}}}
$$

or, with the values $(3 \mathrm{~b})$ and $(5 \mathrm{~b})$,

$$
\mathrm{Z}_{\mathrm{c}, \mathrm{CRLH}-\mathrm{TL}}=\mathrm{Z}_{\mathrm{c}, \mathrm{RH}-\mathrm{TL}}=\mathrm{Z}_{\mathrm{c}, \mathrm{LH}-\mathrm{TL}}
$$


It can be noticed from (12), that for a balanced CRLH-TL, the impedance matching conditions over a large frequency domain can be easily fulfilled.

If the circuit is balanced, then, using $(9)$ in $(7 a, b)$, we get:

$$
\beta_{\text {CRLH-TL }}=\frac{\omega^{2} \mathrm{~L}_{R}^{\prime} C_{L}^{\prime}-1}{\omega \sqrt{L_{L}^{\prime} C_{L}^{\prime}}}=\omega \sqrt{L_{R}^{\prime} C_{R}^{\prime}}-\frac{1}{\omega \sqrt{L_{L}^{\prime} C_{L}^{\prime}}}
$$

From the equation above, it can be noticed that for $\omega>\omega_{0}, \beta_{\mathrm{CRLH}-\mathrm{TL}}>0$, while for $\omega<\omega_{0}, \beta_{\mathrm{CRLH}-\mathrm{TL}}<0$, where $\omega_{0}$ is given in (10).

Using ( $3 \mathrm{a}$ ) and ( $5 \mathrm{a})$, the dispersion equation (13) can be written as follows:

$$
\beta_{\mathrm{CRLH}-\mathrm{TL}}=\beta_{\mathrm{RH}-\mathrm{TL}}+\beta_{\mathrm{LH}-\mathrm{TL}}
$$

From (12) and (14), the equivalent circuit for a balanced CRLH-TL can be drawn by connecting in cascade the equivalent circuits for RH-TL and LH-TL, given in Fig.1 a,b.

\subsection{Equivalent permittivity and permeability}

For a homogenous medium, characterized by $\varepsilon$ and $\mu$ (usually complex values, but real for lossless media), the phase constant, $\beta$, and the characteristic impedance, $Z_{C}$, have the following expressions:

$$
\beta=\omega \sqrt{\varepsilon \mu}, \quad \text { respectively } \quad Z_{C}=\sqrt{\frac{\mu}{\varepsilon}}
$$

From $(15 \mathrm{a}, \mathrm{b})$ and $(1 \mathrm{a}, \mathrm{b})$, for a lossless medium $(\alpha=0)$, we get:

$$
\varepsilon=-j \frac{Y^{\prime}(\omega)}{\omega} \quad \text { and } \quad \mu=-j \frac{Z^{\prime}(\omega)}{\omega}
$$

For a homogenous medium which may be modeled by a RH-TL equivalent circuit, inserting the equations $(2 a, b)$ in $(16 a, b)$, we get:

$$
\varepsilon=\mathrm{C}_{\mathrm{R}}^{\prime} \quad \text { and } \quad \mu=\mathrm{L}_{\mathrm{R}}^{\prime}
$$

For a homogenous medium which may be modeled by a LH-TL equivalent circuit, inserting the equations $(4 a, b)$ in $(16 a, b)$, we get: 


$$
\varepsilon=-\frac{1}{\omega^{2}{ }^{\prime}{ }_{L}^{\prime}} \quad \text { and } \quad \mu=-\frac{1}{\omega^{2} C_{L}^{\prime}}
$$

Likewise, for a homogenous medium, which may be modeled by a CRLH-TL equivalent circuit, inserting the equations $(6 a, b)$ in $(16 a, b)$, we get the following result:

$$
\varepsilon=C_{R}^{\prime}-\frac{1}{\omega^{2} L_{L}^{\prime}} \quad \text { and } \quad \mu=L_{R}^{\prime}-\frac{1}{\omega^{2} C_{L}^{\prime}}
$$

By analyzing the equations $(17 \mathrm{a}, \mathrm{b}),(18 \mathrm{a}, \mathrm{b})$ it is useful to observe that $\varepsilon$ and $\mu$ are positive for RH-TL and negative for a LH-TL, respectively. The equations $(17 \mathrm{a}, \mathrm{b})$ and $(18 \mathrm{a}, \mathrm{b})$ are particular cases of the equations $(19 \mathrm{a}, \mathrm{b})$, for high enough frequencies, respectively for low enough frequencies.

The values of $\varepsilon$ and $\mu$ for CRLH-TL can take either positive or negative values, depending on the frequency. The following conclusions can be drawn by analyzing the relations (19 $a, b)$ and $(8 a, b)$ :

1. If

$$
\omega<{ }^{\omega} \Gamma_{1},
$$

then

$\varepsilon<$

and

$\mu<0$

2. If

$$
\omega>\omega^{\omega} \Gamma_{2}
$$

then

$\varepsilon>0$

and

$\mu>0$

3. If

$$
\omega \in\left({ }^{\omega} \Gamma_{1},{ }^{\omega} \Gamma_{2}\right) \text {, then }
$$

$$
\varepsilon<0 \quad \text { and } \mu>0 \text { if } \frac{1}{\omega \sqrt{L_{L}^{\prime} C_{R}^{\prime}}}>\frac{1}{\omega \sqrt{L_{R}^{\prime} C_{L}^{\prime}}}
$$

or

$$
\varepsilon>0 \quad \text { and } \mu<0 \text { if } \frac{1}{\omega \sqrt{L_{L}^{\prime} C_{R}^{\prime}}}<\frac{1}{\omega \sqrt{L_{R}^{\prime} C_{L}^{\prime}}}
$$

where $\omega^{\omega} \Gamma_{1}$ and $\omega^{\omega} \Gamma_{2}$ are given in $(8 \mathrm{a}, \mathrm{b})$.

For the particular case when the circuit is balanced, if $\omega^{\omega} \Gamma_{1}=\omega_{\Gamma_{2}}=\omega_{0}$ (see equation (10)), the following equations can be obtained:

1. If $\quad \omega<\omega_{0}, \quad \underline{\text { then }} \quad \varepsilon<0$ and $\quad \mu<0$

2. If $\quad \omega>\omega_{0}, \quad \underline{\text { then }} \varepsilon>0$ and $\quad \mu>0$ 
The propagation medium is called metamaterial, if $\varepsilon<0$ and $\mu<0$, inequalities which are valid for low enough frequencies - see (20a) for unbalanced CRLH-TL and (21a) for balanced CRLH-TL.

The analysis performed for an artificial line consisting of cascaded CRLH cells modeled by lumped components leads to similar formulas for the phase shift and for the characteristic impedance (if the length of the cell is much smaller in comparison to the wavelength), but two cut-off frequencies must be taken into account (see also Caloz \& Itoh, 2006). These frequencies are due to the high-pass and low-pass behavior of the CRLH modeled with lumped elements (see section 4 for the formulas of these two frequencies) and cannot be taken into evidence for a distributed transmission line.

\section{Microwave Directional Coupler with CRLH cells on Silicon Substrate}

\subsection{Circuit description, design and fabrication}

The coupler presented here is composed of two coupled artificial CRLH-TLs, each one having two identical cascaded cells, each one consisting of series interdigital capacitors and parallel connected short-ended transmission lines.

The coupler layout, in CPW configuration, is shown in Fig.5. Four tapered lines were used for impedance matching and also to fit the probes sizes to the on-wafer measurement system.

A strong coupling is possible for this type of coupler, as compared to other kinds of couplers as, for instance, the Lange coupler (Caloz \& Itoh, 2005).

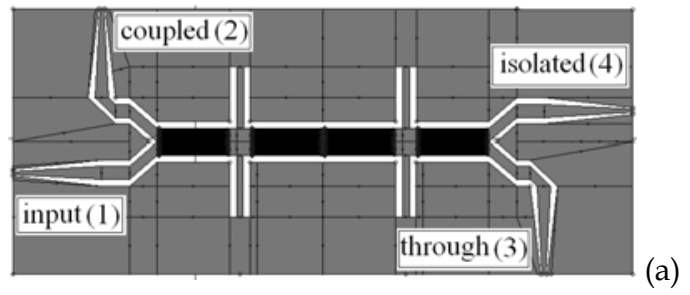

Fig. 5. Complete coupler layout (a) and a layout detail (b) for one CRLH cell.
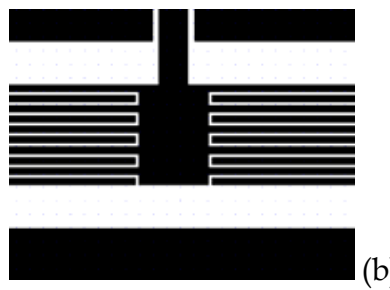

The equivalent circuit for one CRLH cell is given in Fig.6. The series interdigital capacitor has the equivalent capacitance $\mathrm{C}_{\mathrm{Cs}}$, the series equivalent inductance $\mathrm{L}_{\mathrm{Cs}}$ and the parallel equivalent capacitance (to the ground) $\mathrm{C}_{\mathrm{Cp}}$. Also, the short-ended $\mathrm{CPW}$ has the equivalent inductance $\mathrm{L}_{\mathrm{Lp}}$ and the parallel equivalent capacitance, $\mathrm{C}_{\mathrm{Lp}}$.

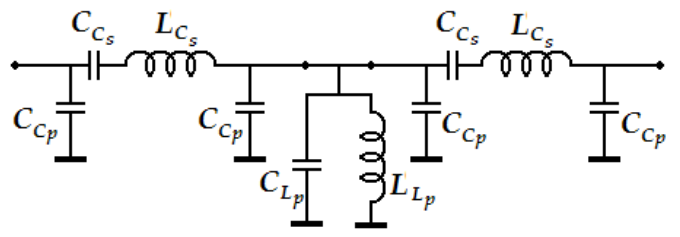

Fig. 6. Equivalent circuit for one CRLH cell. 
The CRLH cell was designed such as to obtain a balanced structure for the central frequency of the coupler. This means that the series frequency of resonance has to be equal to the parallel frequency of resonance and also equal to the central frequency of the coupler (Caloz et al., 2004). Nevertheless, if two CRLH based transmission lines are coupled, the band-stop frequency due to the even/odd mode occurs around the central frequency of the coupler, due to the mutual inductances and the coupling capacitances. The band-stop frequency range is wider as the coupling is stronger.

The substrate used both in simulations and in the experimental approach was a $500 \mu \mathrm{m}$ thick silicon wafer, with a dielectric constant of 11,9 , covered by a $1 \mu \mathrm{m}$ thick thermal $\mathrm{SiO}_{2}$ layer, having the dielectric constant equal to 4.7. The bulk resistivity of the silicon substrate is equal to $5 \mathrm{k} \Omega \mathrm{cm}$.

The design procedure starts with the interdigital capacitor. The numerical value for $C_{C s}$ must be chosen taking into account the central frequency of the coupler, the imposed technological resolution, the finger length (which must be much shorter than the minimum wavelength) and also the condition for the series resonance, which must be equal to the central frequency of the coupler. Taking into account these constrains, the layout of the interdigital capacitor has been optimized by using the software IE3D - Zeland. The numerical results exhibit a series resonance frequency at $\mathrm{f}_{0}=11.25 \mathrm{GHz}$, closed to the impose value. The values for the capacitor equivalent circuit elements $\left(\mathrm{C}_{\mathrm{Cs}}, \mathrm{L}_{\mathrm{Cs}}\right.$ and $\left.\mathrm{C}_{\mathrm{Cp}}\right)$ have been computed using the following formulas:

$$
\mathrm{C}_{\mathrm{Cs}}=\frac{-\operatorname{Im}\left(\mathrm{Y}_{12}\right)}{2 \pi \mathrm{f}}\left[1-\left(\frac{\mathrm{f}}{\mathrm{f}_{0}}\right)^{2}\right] ; \quad \mathrm{L}_{\mathrm{Cs}}=\frac{1}{\left(2 \pi \mathrm{f}_{0}\right)^{2} \mathrm{C}_{\mathrm{Cs}}} ; \quad \mathrm{C}_{\mathrm{Cp}}=\frac{\operatorname{Im}\left(\mathrm{Y}_{11}\right)+\operatorname{Im}\left(\mathrm{Y}_{12}\right)}{2 \pi \mathrm{f}}
$$

where $Y_{11}$ and $Y_{12}$ are the admittance matrix elements of the CPW interdigital capacitor, at low frequency $(\mathrm{f}=1 \mathrm{GHz})$. In this way, using (22), the capacitor circuit elements were computed as: $\mathrm{C}_{\mathrm{Cs}}=0.35 \mathrm{pF}, \mathrm{L}_{\mathrm{Cs}}=0.572 \mathrm{nH}$ and $\mathrm{C}_{\mathrm{Cp}}=0.082 \mathrm{pF}$.

In order to design the whole layout of the CRLH cell, the values for the equivalent circuit elements obtained for the capacitor $\left(\mathrm{C}_{\mathrm{Cs}}, \mathrm{L}_{\mathrm{Cs}}\right.$ and $\left.\mathrm{C}_{\mathrm{Cp}}\right)$ are used to compute $\mathrm{L}_{\mathrm{Lp}}$ and $\mathrm{C}_{\mathrm{Lp}}$. The values for $L_{L p}$ and for the coupler characteristic impedance $Z_{c}$, may be obtained by solving the following equations system:

$$
\frac{\mathrm{L}_{\mathrm{Cs}}}{\mathrm{z}_{\mathrm{C}}^{2}}-2 \mathrm{C}_{\mathrm{Cp}}=\frac{{ }_{\mathrm{Lp}}}{\mathrm{Z}_{\mathrm{cL}}^{2}} \quad ; \quad \frac{\mathrm{L}_{\mathrm{Cs}}}{\mathrm{L}_{\mathrm{Lp}} \mathrm{Z}_{\mathrm{cL}}^{-2}+2 \mathrm{C}_{\mathrm{Cp}}}=\frac{\mathrm{L}_{\mathrm{Lp}}}{\mathrm{C}_{\mathrm{Cs}}}
$$

where $Z_{c L}$ is the characteristic impedance of the CPW stub (see Fig.5). The equations system (22) was solved for $f_{0}=11.25 \mathrm{GHz}$, running $Z_{\mathrm{cL}}$ values to get numerical solutions for the given system. When $Z_{c L}=60 \Omega$, they are obtained $L_{L p}=0.603 n H$ and $Z_{c}=41 \Omega$ (also $\mathrm{C}_{\mathrm{Lp}}=0.167 \mathrm{pF}$ ). With the above data, the resonance frequency of the CPW stub is $11.25 \mathrm{GHz}$, the same as the resonance frequency of the interdigital capacitor (therefore, the CRLH cell is balanced). For the substrate data given above, the values for $L_{L p}$ and $Z_{c}$ may be obtained if the length of the coplanar line is $0.8 \mathrm{~mm}$, the width of the central CPW line is $100 \mu \mathrm{m}$ and 
the width of the CPW slot is $100 \mu \mathrm{m}$. The interdigital capacitor will consist of 10 fingers, having the length equal to $1 \mathrm{~mm}$ and the width equal to $10 \mu \mathrm{m}$. Moreover, the gap between the fingers is equal to $10 \mu \mathrm{m}$.

The numerical results for the design coupler were obtained with IE3D - Zeland software and are presented in the next section.

The circuit was manufactured by means of a standard photolithographic process. A $500 \AA$ Cr layer followed by $0.6 \mu \mathrm{m}$ Au layer were evaporated onto the entire surface of the $1 \mu \mathrm{m} \mathrm{SiO}_{2}$ layer that covers the silicon wafer. After that, the metallization pattern was defined by a usual step of wet etching. A detail of the obtained circuit is shown in Fig.7 (Simion et al., 2008-a).

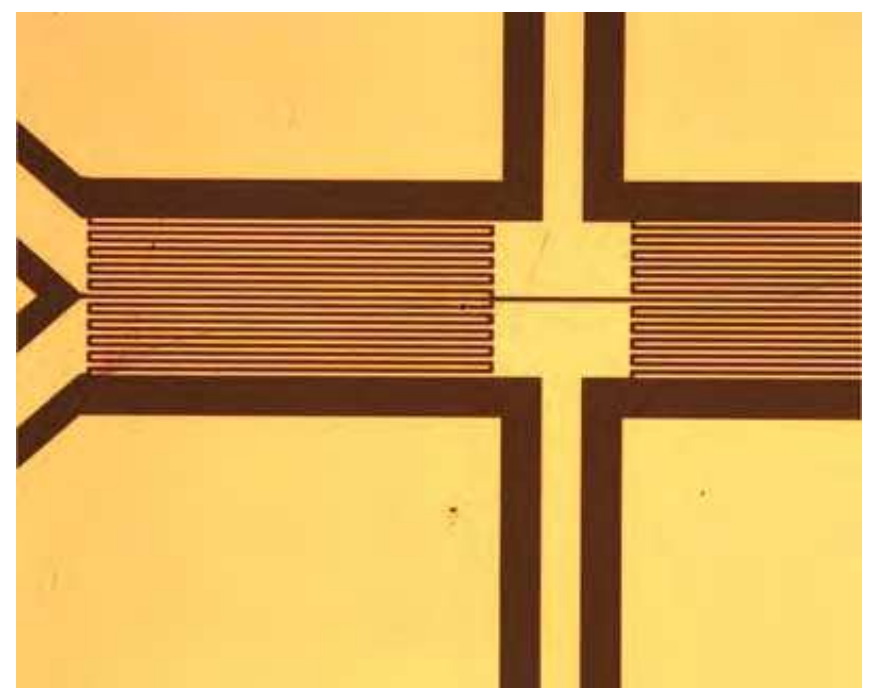

Fig. 7. Microscope photo of the fabricated coupler. Detail for the interdigital capacitors and the CPW stubs area.

\subsection{Experimental characterization method and results}

The fabricated coupler was experimentally characterized using a two-port vector network analyzer and an on-wafer probe heads station. In order to characterize a coupler which is a four-port circuit by using a two-port network analyzer, a similar method as proposed in (Tippet \& Speciale, 1982), was employed (Simion et al., 2008-b).

For a coupler, the number of measurement sets is given by the possible combinations of two-port measurements, $C_{n}^{2}=\frac{n !}{2 !(n-2) !}$, which is equal to 6 , if the number of ports is $\mathrm{n}=4$. So, the proposed method involves 6 measurement sets, performed on the coupler for each frequency. Following these two-port measurements, 6 scattering matrixes, $s_{i-j}$, are obtained, where $i$ and $j$ are the port number (see Fig.5 (a)): $S_{1-2}, S_{1-3}, S_{1-4}, S_{2-3}$, 
$\mathrm{S}_{2-4}$ and $\mathrm{S}_{3-4}$. The scattering matrixes $\mathrm{S}_{\mathrm{i}-\mathrm{j}}$ must be re-normalized to the impedance corresponding to the loads connected to the each port, obtaining 6 scattering parameter matrixes, $S_{i-j}^{\prime}$, according to the formula:

$$
S_{i-j}^{\prime}=\left(I_{2}-\Gamma_{i-j}\right)^{-1} \cdot\left(S_{i-j}-\Gamma_{i-j}\right) \cdot\left(I_{2}-\Gamma_{i-j} \cdot S_{i-j}\right)^{-1} \cdot\left(I_{2}-\Gamma_{i-j}\right)
$$

where $\Gamma_{i-j}=\left[\begin{array}{cc}\Gamma_{i} & 0 \\ 0 & \Gamma_{j}\end{array}\right], \quad \Gamma_{i}$ and $\Gamma_{j}$ are the reflection coefficients of the ports $i$ and $j$, computed for the case when these ports are open-ended (the reference impedance being $50 \Omega$ ) and $I_{2}$ is the unity matrix of order two. Because each port is open, the load impedances or the reflection coefficients at the four ports are not known before. Therefore, first of all, the reflection coefficients of the all four ports, $\Gamma_{1}, \ldots, \Gamma_{4}$ must be computed. Theoretically, these reflection coefficients are equal to 1 , but these values must be known more accurately. The reflection coefficients were computed by solving the following equation system:

$$
\begin{aligned}
& S_{1-2}^{\prime}[1,1]=S_{1-3}^{\prime}[1,1] \\
& S_{1-2}^{\prime}[1,1]=S_{1-4}^{\prime}[1,1] \\
& S_{1-2}^{\prime}[2,2]=S_{2-3}^{\prime}[1,1] \\
& S_{1-2}^{\prime}[2,2]=S_{2-4}^{\prime}[1,1]
\end{aligned}
$$

where $S_{i-j}^{\prime}[1,1]$ is the element of the $S_{i-j}^{\prime}$ matrix from the first row and the first column, while $S_{i-j}^{\prime}[2,2]$ is the element of the $S_{i-j}^{\prime}$ matrix from the second row and the second column.

It may be shown that imposing in $(24)$ the conditions: $S_{1-4}^{\prime}[2,2]=S_{3-4}^{\prime}[2,2]$, $S_{2-4}^{\prime}[2,2]=S_{3-4}^{\prime}[2,2], \quad S_{3-4}^{\prime}[1,1]=S_{2-3}^{\prime}[2,2]$ and $S_{3-4}^{\prime}[1,1]=S_{1-3}^{\prime}[2,2]$ are also fulfilled.

In (24), the analytical expressions for $S_{i-j}^{\prime}[1,1]$ and $S_{i-j}^{\prime}[2,2]$ were developed from (23), obtaining the following formulas: 


$$
S_{i-j}^{\prime}[1,1]=\frac{A}{B} \quad \text { and } \quad S_{i-j}[2,2]=\frac{C}{B}
$$

where:

$$
\begin{aligned}
& A=\left(S_{i-j}[1,1]-\Gamma_{i}\right) \cdot\left(1-S_{i-j}[2,2] \cdot \Gamma_{j}\right)+S_{i-j}[1,2] \cdot S_{i-j}[2,1] \cdot \Gamma_{j} \\
& C=\left(S_{i-j}[2,2]-\Gamma_{j}\right) \cdot\left(1-S_{i-j}[1,1] \cdot \Gamma_{i}\right)+S_{i-j}[1,2] \cdot S_{i-j}[2,1] \cdot \Gamma_{i}
\end{aligned}
$$

and

$$
B=\left(1-S_{i-j}[1,1] \cdot \Gamma_{i}\right) \cdot\left(1-S_{i-j}[2,2] \cdot \Gamma_{j}\right)-S_{i-j}[1,2] \cdot S_{i-j}[2,1] \cdot \Gamma_{i} \cdot \Gamma_{j}
$$

By using (25), the equation system (24) has been solved using the MATHCAD software, obtaining the reflection coefficients $\Gamma_{1}, \ldots, \Gamma_{4}$. Therefore, the all 6 matrixes $S_{i-j}^{\prime}$ were obtained numerically with (23), so, the four port matrix of the coupler having the all ports open-ended was written as follows:

$$
S^{\prime}=\left[\begin{array}{llll}
S_{1-2}^{\prime}[1,1] & S_{1-2}^{\prime}[1,2] & S_{1-3}^{\prime}[1,2] & S_{1-4}^{\prime}[1,2] \\
S_{1-2}^{\prime}[2,1] & S_{1-2}^{\prime}[2,2] & S_{2-3}^{\prime}[1,2] & S_{2-4}^{\prime}{ }^{[1,2]} \\
S_{1-3}^{\prime}[2,1] & S_{2-3}^{\prime}[2,1] & S_{1-3}^{\prime}[2,2] & S_{3-4}^{\prime}[1,2] \\
S_{1-4}^{\prime}[2,1] & S_{2-4}^{\prime}[2,1] & S_{3-4}^{\prime}[2,1] & S_{1-4}^{\prime}[2,2]
\end{array}\right]
$$

Finally, the scattering matrix of the coupler is re-normalized from the load impedances corresponding to the open ports, to $50 \Omega$, using the formula:

$$
\mathrm{S}=\left(\mathrm{I}_{4}-\Gamma\right)^{-1} \cdot\left(\mathrm{S}^{\prime}-\Gamma\right) \cdot\left(\mathrm{I}_{4}-\Gamma \mathrm{S}^{\prime}\right)^{-1} \cdot\left(\mathrm{I}_{4}-\Gamma\right)
$$

where $\mathrm{I}_{4}$ is the unity matrix of order four and $\Gamma=\left[\begin{array}{cccc}-\Gamma_{1} & 0 & 0 & 0 \\ 0 & -\Gamma_{2} & 0 & 0 \\ 0 & 0 & -\Gamma_{3} & 0 \\ 0 & 0 & 0 & -\Gamma_{4}\end{array}\right]$

Using the experimental method proposed above, the coupler has been experimentally characterized (Simion et al., 2008-b).

For the measurements performed on the circuit, a network analyzer (HP 8510C) and onwafer probe heads station (Karl Süss PM5) have been used. These results are presented in Fig. 8 (a), for the magnitude of the scattering parameters S11, S21, S31 and S41. The simulated magnitudes of the scattering parameters S11, S21, S31 and S41 for the test circuit 
are shown in Fig. 8 (b). Fig. 8(c) shows the simulated and the experimental results for the phase difference between the coupled port and the through port.

By analyzing Figs. $8(\mathrm{a}, \mathrm{b})$ for the frequency bandwidth of $10-12 \mathrm{GHz}$, the experimental coupling is $5 \mathrm{~dB} \pm 1 \mathrm{~dB}$, being in good agreement with the simulated results. The experimental input return-loss and isolation are better than $20 \mathrm{~dB}$ for the same frequency bandwidth, a good agreement between simulated and experimental results being also observed. In Fig. 8 (c), the experimental phase is $80-100$ deg., for frequencies between $10.25-11.5 \mathrm{GHz}$, the simulated results being close to the experimental ones.

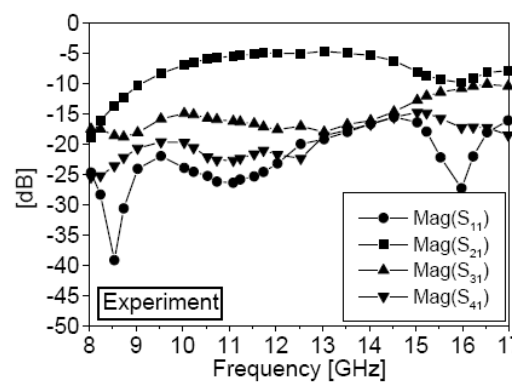

(a)
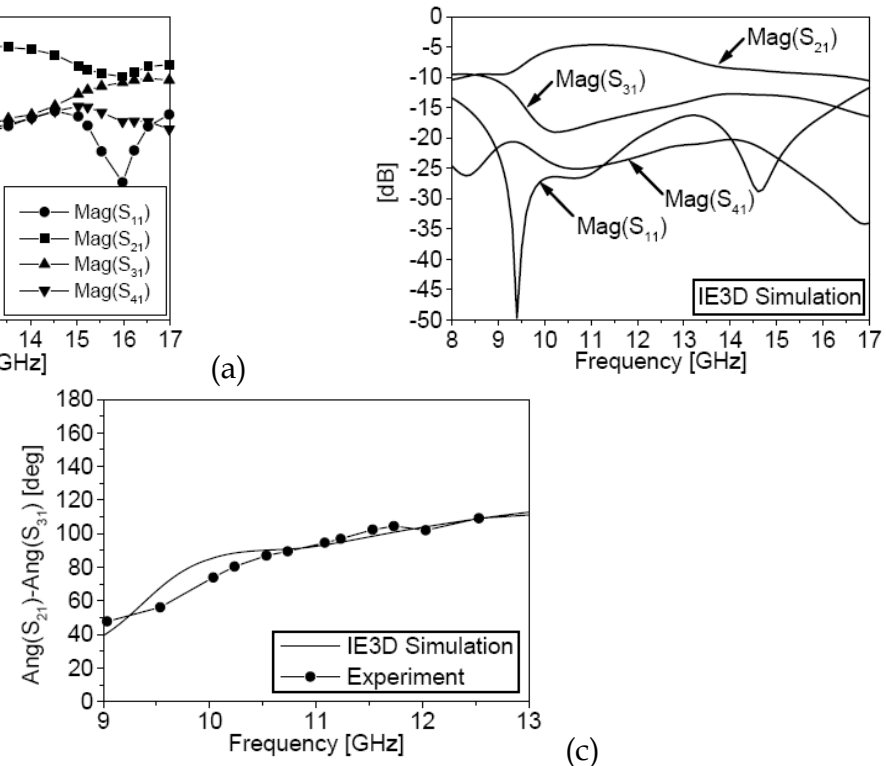

(c)

Fig. 8. (a) Experimental magnitudes of the scattering parameters, for the coupler. (b) Simulated magnitudes of the scattering parameters, for the coupler. (c) Simulated and experimental phase difference between the coupled port and the through port of the coupler.

\section{CRLH Based Silicon Supported Microwave Resonating Antenna}

\subsection{Antenna design and layout}

The antenna consists of an open-ended array of CRLH cascaded cells, each one having a T circuit topology. Each cell consists of two series connected CPW interdigital capacitors and two parallel connected short-ended CPW transmission lines. The equivalent circuit of the CRLH cell is presented in Fig.9, where $2 C_{L}$ and $L_{R} / 2$ are the equivalent capacitance and the equivalent inductance of the series capacitor, while $C_{R}$ and $L_{L}$ are the equivalent parallel capacitance and the equivalent parallel inductance, respectively, of the two $\mathrm{CPW}$ transmission lines.

The parallel capacitance $C_{R}$ includes the equivalent capacitance of the short-ended CPWs and the equivalent parallel capacitance of the interdigital capacitors. 
Using CPW transmission lines, the circuit area could be much smaller comparing to the case when microstrip lines are used, because no large patch area is needed in order to obtain a virtual-ground capacitance used to connect the inductance $\mathrm{L}_{\mathrm{L}}$ to the ground.

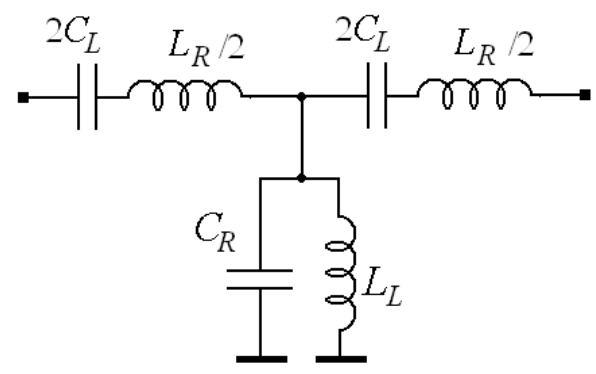

Fig. 9. Equivalent circuit of the CRLH cell used for the antenna design.

For an open-ended CRLH antenna, the zeroth-order resonance occurs at the frequency:

$$
\mathrm{f}_{\mathrm{sh}}=\frac{1}{2 \pi \sqrt{\mathrm{L}_{\mathrm{L}} \mathrm{C}_{\mathrm{R}}}}
$$

which is the parallel resonance due to the two CPW short-ended transmission lines.

Also, there are resonance frequencies corresponding to the right-hand ( $\mathrm{RH}$ ) and the lefthand (LH) CRLH behavior (Caloz \& Itoh, 2006). For the operating frequency of the zerothorder antenna, $\mathrm{f}_{\mathrm{sh}}, \beta=0$ where $\beta$ is the equivalent phase constant of the CRLH cell, this frequency being the highest one for the LH frequency range.

In order to design the CRLH cell, the following formulas must also be used:

$$
\mathrm{f}_{\mathrm{L}}=\frac{1}{4 \pi \sqrt{\mathrm{L}_{\mathrm{L}} \mathrm{C}_{\mathrm{L}}}} ; \quad \mathrm{f}_{\mathrm{R}}=\frac{1}{\pi \sqrt{\mathrm{L}_{\mathrm{R}} \mathrm{C}_{\mathrm{R}}}} ; \quad \mathrm{f}_{\mathrm{se}}=\frac{1}{2 \pi \sqrt{\mathrm{L}_{\mathrm{R}} \mathrm{C}_{\mathrm{L}}}} ; \quad \mathrm{Z}_{\mathrm{C}}=\sqrt{\frac{\mathrm{L}_{\mathrm{L}}}{\mathrm{C}_{\mathrm{L}}}}
$$

where $f_{L}$ and $f_{R}$ are the cutoff frequencies for the LH and RH modes respectively, $f_{s e}$ is the series resonance of the interdigital capacitor and $Z_{C}$ is the $L H$ characteristic impedance. The frequency range for the $\mathrm{LH}$ mode extends from $f_{L}$ to $f_{s h}$, while the frequency range for $\mathrm{RH}$ mode extends from $f_{s e}$ to $f_{R}$. The condition to be fulfilled for these frequencies is $\mathrm{f}_{\mathrm{R}}>\mathrm{f}_{\mathrm{se}}>\mathrm{f}_{\mathrm{sh}}>\mathrm{f}_{\mathrm{L}}$.

The starting point in designing the capacitor was to consider the $10 \mu \mathrm{m}$ width of a metallic line, the length of the capacitor fingers of $0.5 \mathrm{~mm}$ (much smaller comparing to the operating wavelengths) and the resonance frequency $f_{\text {sh }}=14 \mathrm{GHz}$ (Simion et al., 2007-a). The preliminary values for the elements of the CRLH equivalent circuit (see Fig.9) have been computed using (26) - (30), for $Z_{C}=50 \Omega$ and the CPW characteristic impedance equal to $60 \Omega$ in order to minimize the losses. After that, the layout of an elementary CRLH cell was designed and optimized. Finally, for the layout of a CRLH cell, the following results were obtained: CPWs length - $1.5 \mathrm{~mm}$; CPWs central conductor width - $100 \mu \mathrm{m}$; width of the 
CPWs slot $-100 \mu \mathrm{m}$; length of the interdigital capacitor at the end of the antenna $-1 \mathrm{~mm}$; length of the internal interdigital capacitor $-0.5 \mathrm{~mm}$; width of the metallic finger of the interdigital capacitor - $10 \mu \mathrm{m}$; space between two fingers of the interdigital capacitor $10 \mu \mathrm{m}$; space between the interdigital capacitor and the ground planes of the CPW structure $-100 \mu \mathrm{m}$ and the number of the metallic fingers of the interdigital capacitor -10 .

For this layout, the elements of the CRLH equivalent circuit were computed, obtaining (see Fig.9): $\mathrm{L}_{\mathrm{L}}=0.55 \mathrm{nH}, \mathrm{C}_{\mathrm{L}}=0.18 \mathrm{pF}, \mathrm{L}_{\mathrm{R}}=0.3 \mathrm{nH}$ and $\mathrm{C}_{\mathrm{R}}=0.23 \mathrm{pF}$, corresponding to $\mathrm{f}_{\mathrm{L}}=8 \mathrm{GHz}, \mathrm{f}_{\mathrm{sh}}=14 \mathrm{GHz}, \mathrm{f}_{\mathrm{se}}=22 \mathrm{GHz}$ and $\mathrm{f}_{\mathrm{R}}=38 \mathrm{GHz}$.

The zeroth-order resonating antenna consists of three identical CRLH cells as it is shown in Fig.10. Each cell has the geometrical dimensions previously given. A CPW line of $4.5 \mathrm{~mm}$ length was used to connect the device to the measuring system.

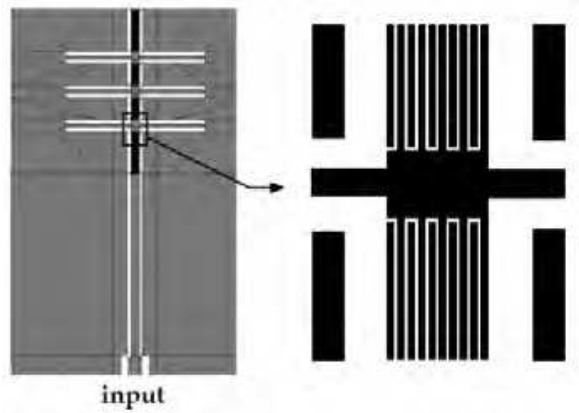

Fig. 10. The antenna layout and a detail for the area around the junction between the CPW interdigital capacitors and the inductive CPW stubs.

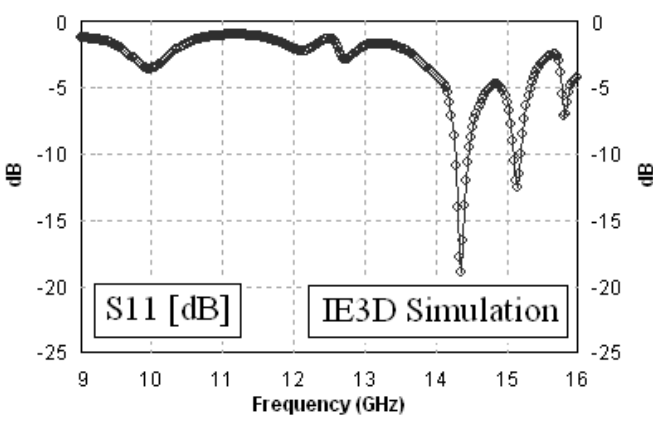

(a)

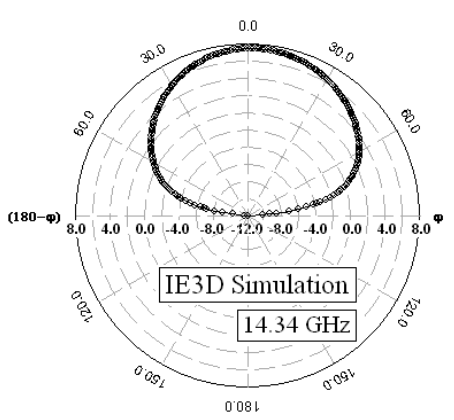

(b)

Fig. 11. (a) Simulated return-loss of the CPW CRLH resonating antenna; (b) Elevation pattern gain for the CPW CRLH resonating antenna, displayed for the total electrical field.

In Fig.11 (a) and (b) the simulated parameters of the antenna - return-loss and radiation pattern - are presented.

It may be seen from Fig.11 (a) that the return-loss is close to $20 \mathrm{~dB}$ at $14.34 \mathrm{GHz}$ which is the zeroth-order resonance frequency. Another resonance at $15.2 \mathrm{GHz}$ corresponds to the series resonance of the first and the last interdigital capacitors which are longer compared to the 
internal ones. The antenna gain - see Fig.11 (b) - is around $7.5 \mathrm{dBi}$ at the zeroth-order resonance frequency.

\subsection{Antenna technological realization and experimental results}

The technological process for antenna fabrication was the same as for the coupler previously presented - see section 3. The microscope photo of the antenna active area is shown in Fig.12(a). The area occupied by the antenna is $3.9 \times 3.4 \mathrm{~mm}^{2}$, showing a size reduction of approx. $30 \%$, in comparison to a $\lambda / 2$ patch antenna. The measurements of antenna return losses were performed using a network analyzer and an on-wafer probe heads station. In order to measure the antenna gain and pattern of the radiating beam, a mechanical system involving two antennas was prepared. Each antenna was mounted on a SMA connector test fixture, as it is shown in Fig.12(b).
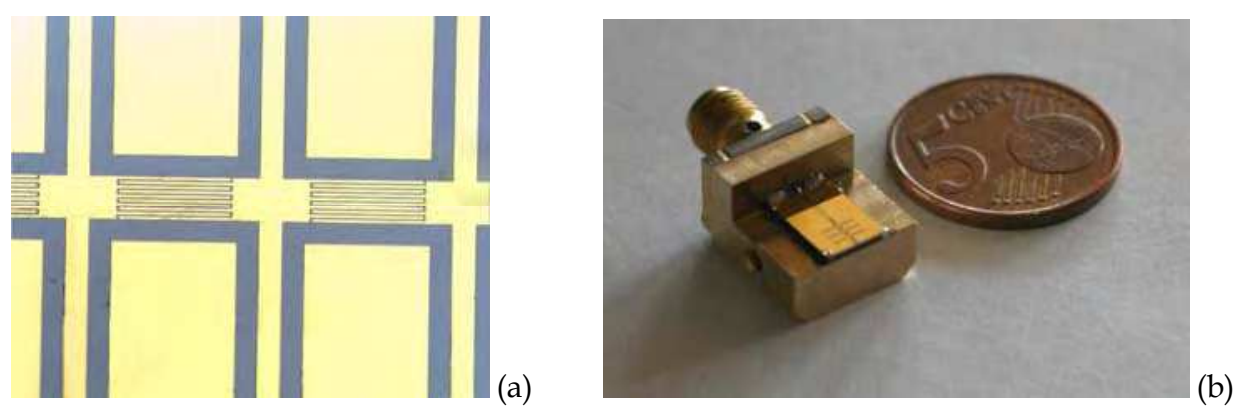

Fig. 12. (a) Microscope photo of the active part of the obtained antenna; (b) Antenna mounted on a SMA test fixture for the gain and radiation pattern measurements

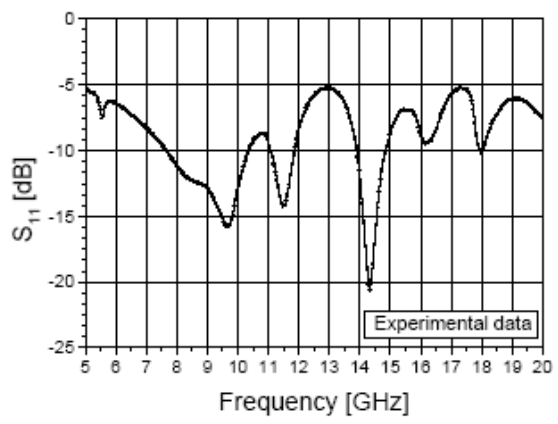

(a)

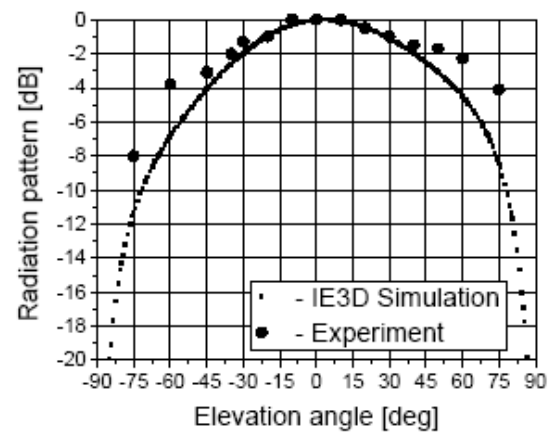

Fig. 13. (a) Measured return-loss of the CPW CRLH resonating antenna; (b) Simulated and measured $\mathrm{E}$ - plane radiation pattern for the CPW CRLH resonating antenna.

Fig.13 (a) shows the measured return-loss of the CPW CRLH resonating antenna and Fig.13 (b) presents the simulated and measured E - plane radiation pattern for the CPW CRLH resonating antenna. It can be observed, that the resonance frequency and the returnloss at this frequency are quite the same as they were predicted by simulation. The errors are less than $0.2 \%$ for the resonance frequency and around $2 \mathrm{~dB}$ for the return-loss. 
For the gain measurement, the two antenna method and the Friis formula, (Balanis, 1997), were used. The distance between the two antennas was $6 \times \lambda$ and the magnitude of $S_{21}$ at the resonance frequency was measured for this antenna system. Following this procedure, the measured value for the antenna gain was $6.4 \mathrm{dBi}$ meaning a $\sim 1 \mathrm{~dB}$ difference from the simulated value.

\section{Frequency Tuning of a CPW CRLH Antenna on Magnetically Biased Ferrite Substrate}

\subsection{CRLH antenna on magnetically biased ferrite substrate}

The substrate used was a polycrystalline ferrite having the saturation magnetization Ms $=550$ Gs, permittivity $\varepsilon=13.5$, resonance linewidth $\Delta \mathrm{H}=16.8 \mathrm{kA} / \mathrm{m}$. The thickness of the ferrite substrate was $0.5 \mathrm{~mm}$ and the surface to be metallized was mirror polished. The antenna layout was designed for an external applied field $\mathrm{H}_{\mathrm{appl}}=0 \mathrm{~T}$, namely, for the ferrite substrate in unmagnetized state, using the same method as presented in Section 4.

If a dc biasing magnetic field $\left(\mathrm{H}_{\mathrm{appl}}\right)$ is applied normally to the ferrite substrate, the permeability changes its values from the unpolarized state. For the biasing magnetic field varying from $\mathrm{H}_{\mathrm{appl}}=0 \mathrm{~T}$ to $\mathrm{H}_{\mathrm{appl}}=0,26 \mathrm{~T}$ the effective permeability $\left(\mu_{\text {eff }}\right)$ of the chosen ferrite substrate varies from $\mu_{\text {eff }} \cong 1$ to $\mu_{\text {eff }}=0.921$ respectively, as it is shown in Fig.14. The computation was done (Lax \& Button, 1962) for a frequency $\mathrm{f}=13 \mathrm{GHz}$.

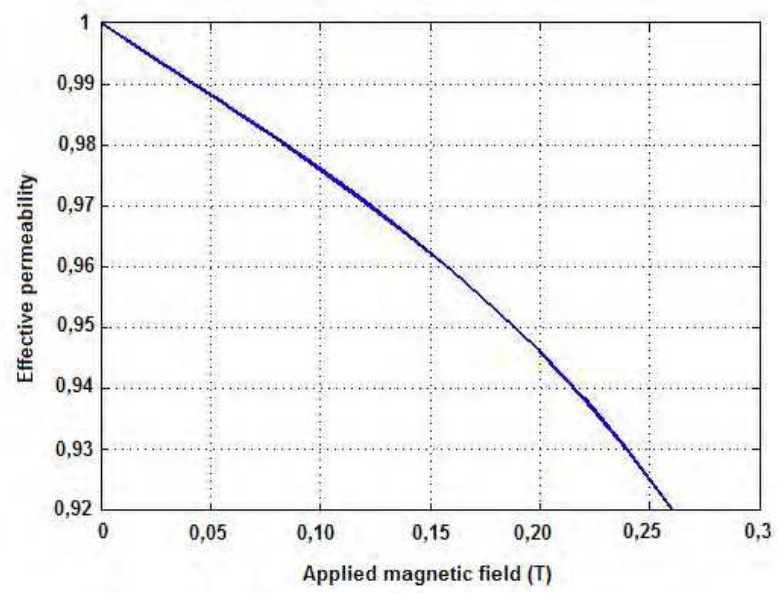

Fig. 14. Effective permeability vs. applied magnetic field

The simulation of the antenna return-loss vs. frequency was carried out for four values of $\mu_{\mathrm{eff}}$ in the above range, corresponding to four intensities of the biasing magnetic field. The maximum value of the return-loss and the frequency for each value of the intensity of the magnetic biasing field are specified in Table 1. 


\begin{tabular}{|c|c|c|c|}
\hline $\begin{array}{c}\text { Applied } \\
\text { magnetic } \\
\text { fied (T) }\end{array}$ & $\begin{array}{c}\text { Effective permeability } \\
\left(\mu_{\text {eff }}\right)\end{array}$ & $\begin{array}{c}\text { Resonance frequency } \\
(\mathbf{G H z})\end{array}$ & $\begin{array}{c}\text { Return losses } \\
(\mathbf{d B})\end{array}$ \\
\hline 0 & 1 & 12.88 & -28.00 \\
\hline 0.055 & 0.986 & 12.96 & -20.26 \\
\hline 0.18 & 0.951 & 13.20 & -22.30 \\
\hline 0.26 & 0.921 & 13.41 & -17.70 \\
\hline
\end{tabular}

Table 1. Computed antenna operating frequency and the corresponding return losses, when the ferrite substrate is magnetically polarized

The calculated values of $S_{11}$ vs. frequency for the effective permeability values are shown in the graphs in Fig.15 (a)...(d). It must be noted that for this domain of the applied field the antenna structure works under the gyromagnetic resonance.

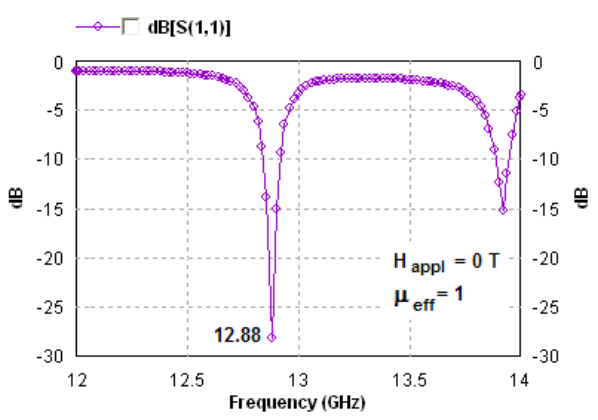

(a)

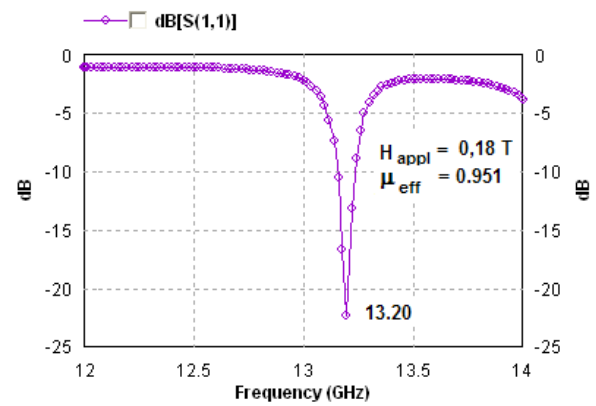

(c)

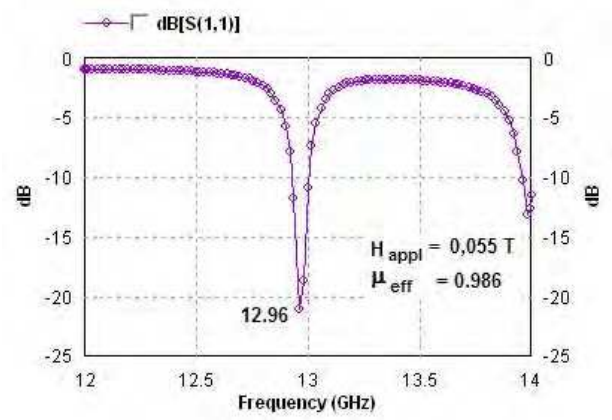

(b)

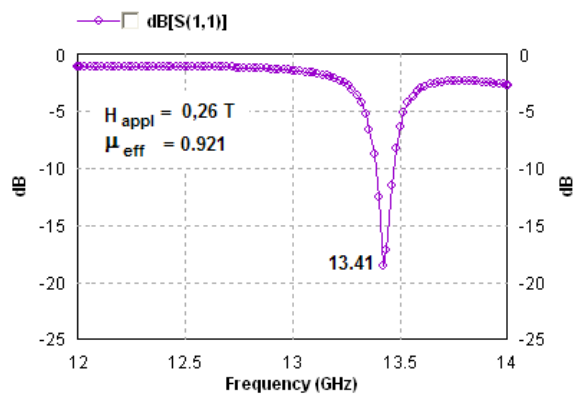

(d)

Fig.15 (a) - (d). Simulated return-loss for the CPW CRLH resonating antenna for four values of the biasing magnetic field.

It must be observed that the zeroth-order resonance frequency calculated in the absence of the magnetic biasing field was found as $12.88 \mathrm{GHz}$ with a return losses level of $28 \mathrm{~dB}$ - see Fig.15 (a). There is another parasitic resonance at $13.9 \mathrm{GHz}$ corresponding to the series resonance of the first interdigital capacitors. When the biasing magnetic field is applied, the calculated frequency for the antenna structures ranges from $12.88 \mathrm{GHz}$ for $\mathrm{H}_{\mathrm{appl}}=0$ to $13.41 \mathrm{GHz}$ for $\mathrm{H}_{\mathrm{appl}}=0.26 \mathrm{~T}$. Also, the calculated reflection losses changes from $28 \mathrm{~dB}$ at 
$\mathrm{H}_{\text {appl }}=0$ to approx. $17.7 \mathrm{~dB}$ for $\mathrm{H}_{\text {appl }}=0.26 \mathrm{~T}$. Therefore a very good impedance matching is obtained for the operating frequency range.

\subsection{Experimental results}

The technological process for manufacturing the antenna was the same as for the coupler (see section 3).

The individual antenna structures obtained by cutting the ferrite wafer were mounted on suitable test fixtures - see Fig.16 (a) - in a measurement system able to measure microwave frequency and reflection losses while applying a biasing static magnetic field normally on the ferrite antenna substrate - see Fig.16 (b). In Fig.16 (b) number 1 denotes the antenna structure mounted on a test fixture, 2 denotes polar pieces of the electromagnet, the superior one being movable and 3 is the Hall sensor of a tesla-meter.

The experimental results concerning the measured resonating frequencies and return losses (RL) of two antenna structures, are shown in Table 2 and in Fig.17 (a) - (b).

\begin{tabular}{|c|c|c|c|c|}
\hline \multirow{2}{*}{$\mathbf{H}_{\text {appl. }}(\mathbf{T})$} & \multicolumn{2}{|c|}{ Antenna structure 1 } & \multicolumn{2}{c|}{ Antenna structure 2 } \\
\cline { 2 - 5 } & Freq. $(\mathbf{G H z})$ & $\mathbf{R L} \mathbf{( - d B )}$ & Freq. $\mathbf{( G H z )}$ & RL (-dB) \\
\hline 0 & 13.35 & 25 & 13.57 & 18 \\
\hline 0.02 & 13.35 & 25 & 13.57 & 18 \\
\hline 0.04 & 13.35 & 25 & 13.57 & 18 \\
\hline 0.055 & 13.35 & 26 & 13.57 & 19 \\
\hline 0.06 & 13.35 & 26 & 13.58 & 19 \\
\hline 0.07 & 13.35 & 27 & 13.59 & 19 \\
\hline 0.08 & 13.38 & 27 & 13.60 & 19 \\
\hline 0.10 & 13.4 & 27 & 13.61 & 19 \\
\hline 0.12 & 13.41 & 28 & 13.64 & 19 \\
\hline 0.14 & 13.44 & 26 & 13.67 & 19 \\
\hline 0.16 & 13.49 & 26 & 13.70 & 19 \\
\hline 0.18 & 13.51 & 24 & 13.74 & 18 \\
\hline 0.20 & 13.58 & 22 & 13.78 & 17 \\
\hline 0.22 & 13.63 & 21 & 13.81 & 17 \\
\hline 0.24 & 13.70 & 20 & 13.89 & 16 \\
\hline 0.26 & 13.8 & 18 & 13.97 & 14 \\
\hline
\end{tabular}

Table 2. The experimentally obtained resonating frequencies and return losses of the measured antennas vs. magnetic biasing field. 


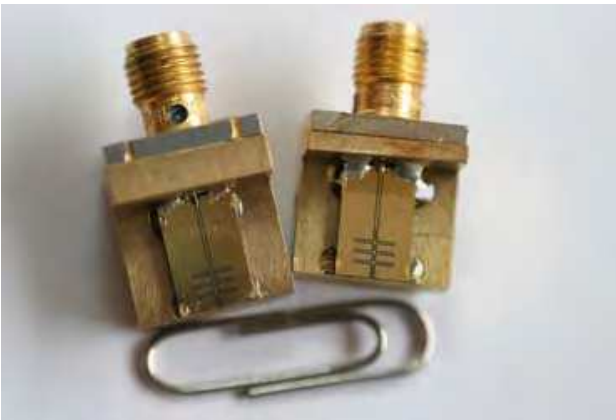

(a)

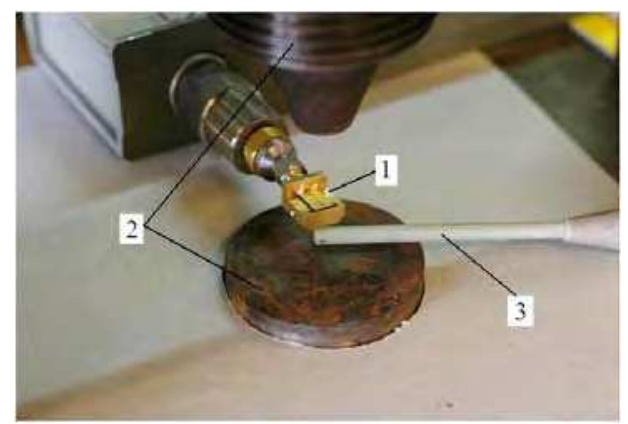

(b)

Fig. 16. (a) SMA test fixture supporting the fabricated CPW CRLH zeroth-order resonating antenna on ferrite substrate; (b) Test fixture with antenna structure in an applying magnetic field facility during $S_{11}$ measurements.

The curves showing the frequency variation of the two antennas - see Fig.17 (a) - and return losses variation - see Fig.17 (b) - as function of the applied magnetic field were obtained using the data from Table 2.

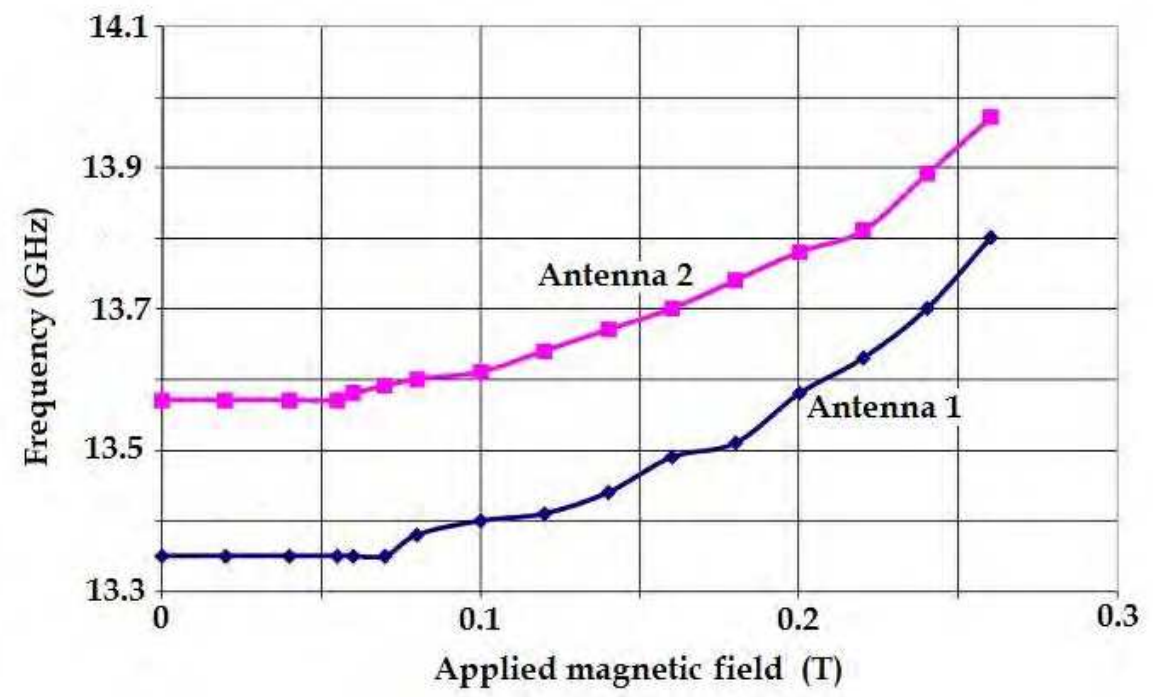

Fig. 17. (a) Frequency shift vs. applied magnetic field;

It can be observed that for a magnetic biasing field less than $0.55 \mathrm{~T}$, the resonating frequencies of the two antennas were $13.57 \mathrm{GHz}$ and $13.35 \mathrm{GHz}$, respectively, slightly higher than the simulated results (see Table 1). This difference between the calculated and measured resonance frequency at low $\mathrm{H}_{\text {appl }}$ is due to some technological limitations in obtaining the exact geometry size of each antenna structure. 
If the applied magnetic field remains under the value of the saturation magnetization, (550 Gs), the working frequencies almost maintain their initial values. At higher values of $\mathrm{H}_{\text {appl, }}$, the resonance frequencies of the antennas tend to increase, as it may be seen in Table 2 and in Fig.17(a). The total measured frequency shift was $400 \mathrm{MHz}$ for the first antenna structure and $450 \mathrm{MHz}$ for the second one, when the biasing magnetic field varied from $\mathrm{H}_{\mathrm{appl}}=0$ to $\mathrm{H}_{\mathrm{appl}}=0.26 \mathrm{~T}$. This frequency shift fits very well with the calculated values (see Table 1).

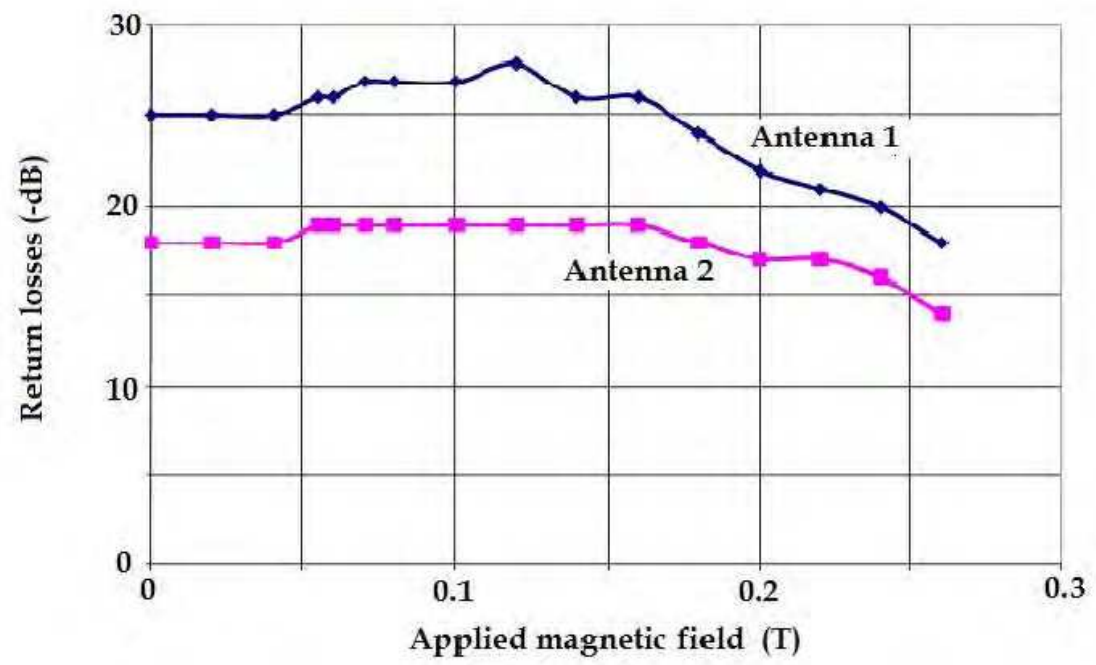

Fig. 17. (b) Return losses vs. applied magnetic field.

The measured return losses of the two antenna structures are presented in Fig.17 (b). It is observed that the experimental values for the return loss and the simulated values given in Table 1 are in very good agreement.

\section{Conclusion}

The chapter presents applications of CRLH structures, including a directional coupler and a resonating antenna both fabricated on silicon substrate, in order to facilitate the future device integration in a more complex monolithic integrated circuit. Also, a resonating antenna on magnetically polarized ferrite has been fabricated and experimentally tested.

CPWs were used for all these devices and a full-wave electromagnetic analysis software (IE3D - Zeland) was used for the design methods.

The experimental coupling of the coupler is $5 \mathrm{~dB} \pm 1 \mathrm{~dB}$, for a frequency bandwidth of $10-12 \mathrm{GHz}$. Also, the experimental input return-loss and isolation are better than $20 \mathrm{~dB}$ for the same frequency bandwidth, a good agreement between simulated and experimental results being also observed. The phase difference between the ports 2 and 3 is $90^{\circ} \pm 10^{\circ}$, for a frequency bandwidth from $10.5 \mathrm{GHz}$ to $12.25 \mathrm{GHz}$. All these experimental results are in good agreement with the expected ones obtained by simulation. 
The experimental operating frequency and the return-loss of the antenna fabricated on silicon substrate is $\sim 14.5 \mathrm{GHz}$ and $\sim 20 \mathrm{~dB}$, showing a good agreement in comparison to the simulation results (errors less than $0.2 \%$ for the resonance frequency and around $2 \mathrm{~dB}$ for the return-loss on the resonance frequency). Also, the experimental results for the gain and for the radiation pattern show a good agreement compared to the simulation results (for the gain, the error is around $1 \mathrm{~dB}$ ).

Concerning the ferrite supported antenna, the experimental data shows a frequency shift of $400 \mathrm{MHz}$ for one of the antenna structures and $450 \mathrm{MHz}$ for the other one, due to the variation of the effective permeability of the ferrite substrate. This work demonstrates the possibility to tune a CRLH antenna made on a ferrite substrate by varying the biasing magnetic field. For this type of antenna, again, the experimental results are very close to the simulation results.

\section{References}

Balanis C. A. (1997). Antenna theory - Analysis and design, John Wiley \& Sons Inc., ISBN 0471-59268-4, New York.

Caloz C., Itoh T. (2003). Positive/negative refractive index anisotropic 2-D metamaterials, IEEE Microwave and Wireless Components Letters, Vol.13, No.12, pp. 547-549, ISSN 1531-1309.

Caloz C., Sanada A., T. Itoh T. (2004). A novel composite right-/left-handed coupled-line directional coupler with arbitrary coupling level and broad bandwidth", IEEE Trans. on Microwave Theory and Techniques, Vol.52, No.3, pp.980-992, ISSN 00189480.

Caloz C., Itoh T. (2005). Metamaterials for high-frequency electronics. Proc. of the IEEE, Vol. 93, No. 10, pp. 1744-1752, ISSN 0018-9219

Caloz C., Itoh T. (2006). Electromagnetic metamaterials: transmission line theory and microwave applications, John Wiley \& Sons, Inc., ISBN-10: 0-471-66985-7, USA, Canada.

Engheta N., Ziolkowski R. W. (2005). A positive future for double-negative metamaterials. IEEE Trans. on Microwave Theory and Techniques, Vol.53, No.4, pp. 1535-1556, ISSN 0018-9480.

Kodera T., Caloz C. (2008). Comparison of various ferrite-loaded CRLH leaky-wave antenna structures. Proc. of Asia-Pacific Microwave Conference, Paper J3-06, ISBN 978-1-42442642-3, Hong Kong, Republic of China, December 2008, Hong Kong and Macau.

Lai A., Caloz C., Itoh T. (2004). Composite right/left-handed transmission line metamaterials. IEEE Microwave Magazine, Vol. 5, No. 3, Sept.2004, pp. 34 - 50, ISSN 1527-3342

Lax B., Button K. J. (1962). Microwave Ferrites and Ferrimagnetics, USA: McGraw-Hill Book Comp., Inc., New York.

Li C., Liu Y. K., Li F. (2007). Analysis of composite right/left-handed coplanar waveguide zeroth-order resonators with application to a band-pass filter. PIERS Online, vol.3, no.5, 2007, pp.599-602.

Lim S., Caloz C., Itoh T. (2004). Metamaterial-based electronically controlled transmissionline structure as a novel leaky-wave antenna with tunable radiation angle and beamwidth. IEEE Trans. on Microwave Theory and Techniques, Vol.52, No.12, pp.2678 - 2690, ISSN 0018-9480. 
Lin I.-H., Caloz C., Itoh T. (2003). A branch-line coupler with two arbitrary operating frequencies using left-handed transmission lines", IEEE MTT-S Digest, 2003, pp.325-328. ISBN 0-7803-7695-1, Philadelphia, Pennsylvania, June 2003

Okabe H., Caloz C., Itoh T. (2004), "A compact enhanced-bandwidth hybrid ring using an artificial lumped-element left-handed transmission-line section", IEEE Trans. on Microwave Theory and Techniques, vol.52, no.3, pp.798-804, ISSN 0018-9480.

Sajin G., Simion S., Craciunoiu F., Marcelli R. (2007). Silicon supported microwave zerothorder resonance antenna on metamaterial approach, Proceedings of the 2007 AsiaPacific Microwave Conference, APMC 2007, pp.221-224, ISBN 1-4244-0748-6, Bangkok, Thailanda, December 2007.

Sajin G., Simion S, Craciunoiu F., Muller A., Bunea A. C. (2009). Frequency Tuning of a CRLH CPW Antenna on Ferrite Substrate by Magnetic Biasing Field. Accepted paper for European Microwave Conference, EuMW 2009, Rome, Italy, SeptemberOctober 2009.

Sanada A., Kimura M., Awai I., Caloz C., Itoh T. (2004). A planar zeroth-order resonator antenna using a left-handed transmission line. Proc. of the $34^{\text {th }}$ European Microwave Conference, pp.1341-1344, Amsterdam, The Netherlands, October 2004, Horizon House, Amsterdam.

Sievenpiper D., Zhang L., Broas R. F. J., Alexopolous N. G., Yablonovitch E. (1999). High impedance electromagnetic surfaces with a forbidden frequency band. IEEE Trans. on Microwave Theory and Techniques, Vol.47, No.11, pp. 2059-2074, ISSN 0018-9480.

Simion S., Sajin G., Marcelli R., Craciunoiu F., Bartolucci G. (2007-a). Silicon Resonating Antenna Based on CPW Composite Left/Right-Handed Transmission Line, Proc. of the 37th European Microwave Conference, pp. 478 - 481, ISBN 978-2-87487-000-2, Munchen, Germany, October 2007.

Simion S., Marcelli R., Sajin G. (2007-b). Small size CPW silicon resonating antenna based on transmission-line meta-material approach, Electronics Letters, Vol.43, No.17, pp.908909, ISSN 0093-5914.

Simion S., Marcelli R., Bartolucci G., Sajin G. (2008-a). Design, Fabrication and On-Wafer Characterization of a Meta-Material Transmission Line Coupler, International Journal of Microwave and Optical Technology - IJMOT, Vol.3, No.3, pp. 363-369. ISSN 1553-0396.

Simion S., Marcelli R., Bartolucci G., Sajin G., (2008-b). On wafer experimental characterization for a 4-port circuit using a two-port vector network analyzer, Proc. of the 31rst International Semiconductor Conference, CAS-2008, pp. 223-226, ISBN 9781-4244-2004-9; ISSN 1545-827X, Sinaia, Romania, October 2008.

Tippet J. C., Speciale R. A. (1982). A rigorous technique for measuring the scattering matrix of a multiport device with a 2-port network analyzer. IEEE Trans. on Microwave Theory and Techniques, Vol.30, No.5, pp. 661 - 666, ISSN 0018-9480.

Tong W., Hu Z., Chua H. S., Curtis P. D., Gibson P. A. A., Missous M. (2007). Left-handed metamaterial coplanar waveguide components and circuits in GaAs MMIC technology, IEEE Trans. on Microwave Theory and Techniques, vol.55, no.8, August 2007, pp.1794-1800.

Veselago V.G. (1968). The electrodynamics of substances with simultaneously negative values of $\varepsilon$ and $\mu$. Sov. Physics - Usp., vol.47, January-February 1968, pp. $509-514$. 


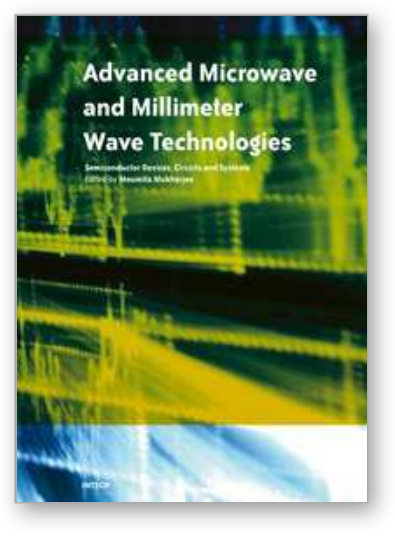

\section{Advanced Microwave and Millimeter Wave Technologies Semiconductor Devices Circuits and Systems}

Edited by Moumita Mukherjee

ISBN 978-953-307-031-5

Hard cover, 642 pages

Publisher InTech

Published online 01, March, 2010

Published in print edition March, 2010

This book is planned to publish with an objective to provide a state-of-the-art reference book in the areas of advanced microwave, MM-Wave and $\mathrm{THz}$ devices, antennas and systemtechnologies for microwave communication engineers, Scientists and post-graduate students of electrical and electronics engineering, applied physicists. This reference book is a collection of 30 Chapters characterized in 3 parts: Advanced Microwave and MM-wave devices, integrated microwave and MM-wave circuits and Antennas and advanced microwave computer techniques, focusing on simulation, theories and applications. This book provides a comprehensive overview of the components and devices used in microwave and MM-Wave circuits, including microwave transmission lines, resonators, filters, ferrite devices, solid state devices, transistor oscillators and amplifiers, directional couplers, microstripeline components, microwave detectors, mixers, converters and harmonic generators, and microwave solid-state switches, phase shifters and attenuators. Several applications area also discusses here, like consumer, industrial, biomedical, and chemical applications of microwave technology. It also covers microwave instrumentation and measurement, thermodynamics, and applications in navigation and radio communication.

\section{How to reference}

In order to correctly reference this scholarly work, feel free to copy and paste the following:

Stefan Simon, Romolo Marcelli, Giancarlo Bartolucci, Florea Craciunoiu, Andrea Lucibello, Giorgio De Angelis, Andrei A. Muller, Alina Cristina Bunea and Gheorghe loan Sajin (2010). Composite Right / Left Handed (CRLH) Based Devices for Microwave Applications, Advanced Microwave and Millimeter Wave Technologies Semiconductor Devices Circuits and Systems, Moumita Mukherjee (Ed.), ISBN: 978-953-307-031-5, InTech, Available from: http://www.intechopen.com/books/advanced-microwave-and-millimeter-wave-technologiessemiconductor-devices-circuits-and-systems/composite-right-left-handed-crlh-based-devices-for-microwaveapplications

\section{INTECH}

open science | open minds

\section{InTech Europe}

University Campus STeP Ri

Slavka Krautzeka 83/A

51000 Rijeka, Croatia

Phone: +385 (51) 770447

\section{InTech China}

Unit 405, Office Block, Hotel Equatorial Shanghai

No.65, Yan An Road (West), Shanghai, 200040, China

中国上海市延安西路65号上海国际贵都大饭店办公楼 405 单元

Phone: +86-21-62489820 
Fax: +385 (51) 686166

Fax: +86-21-62489821

www.intechopen.com 
(C) 2010 The Author(s). Licensee IntechOpen. This chapter is distributed under the terms of the Creative Commons Attribution-NonCommercialShareAlike-3.0 License, which permits use, distribution and reproduction for non-commercial purposes, provided the original is properly cited and derivative works building on this content are distributed under the same license. 